\title{
Antiidiotypic Antibodies to Sperm in Sera of Fertile Women That Neutralize Antisperm Antibodies
}

\author{
Rajesh K. Naz, * Khaliq Ahmad, ${ }^{*}$ and Alan C. Menge \\ * Reproductive Immunology and Molecular Biology Labs, Department of Obstetrics and Gynecology, The Albert Einstein College of \\ Medicine, Bronx, New York 10461; and ${ }^{\ddagger}$ Department of Obstetrics and Gynecology, The University of Michigan Medical School, \\ Ann Arbor, Michigan 48109
}

\begin{abstract}
The presence of antiidiotypic antibodies (ab-2) to sperm was investigated in the sera of fertile, infertile, and virgin women using sperm-specific anti-FA-1 monoclonal antibody Fab'. ab-2 were detected in $71 \%(17 / 24)$ of sera from fertile women and in none $(0 / 12)$ of the sera from virgin females by the enzymelinked immunosorbent assay, Western blot procedure, and immunoprecipitation procedure. Sera from infertile women that had antisperm antibodies showed a minimal presence of ab-2, with only three sera $(13 \%, 3 / 23)$ demonstrating the presence of low levels of $a b-2$. The ab-2 present in fertile women were capable of neutralizing the fertilization-inhibitory activity of anti-FA-1 antibody in a concentration-dependent manner in a human sperm penetration assay (SPA) of zona-free hamster oocytes. ab-2 were also capable of inhibiting the binding of antisperm antibodies to the sperm surface as determined by the immunobead binding technique. This is the first report demonstrating the presence of ab- 2 in the sera of fertile women that are capable of neutralizing antisperm antibodies present in sera of infertile women. These findings suggest that the inability to detect antisperm antibody activity in the sera of fertile women may be due to higher levels of ab-2 present in these sera than levels found in sera of infertile women, although both groups may be producing antisperm antibody response after sexual exposure to sperm. (J. Clin. Invest. 1993. 92:2331-2338.) Key words: antisperm antibodies $\bullet$ antiidiotypic antibodies $\bullet$ infertility $\bullet$ sperm penetration assay $\bullet$ sperm antigens
\end{abstract}

\section{Introduction}

Spermatozoa have both auto- as well as isoantigenic potentials in humans. Up to $70 \%$ of vasectomized men form antisperm antibodies ( 1 ) and up to $30 \%$ of infertility (having unexplained or immunologic etiologies) may be associated with the presence of antisperm antibodies in the male and/or female partner of an infertile couple (2). In the female genital tract, the components of mucosal immunity and systemic immunity have been detected in different combinations from the vagina to the ovarian follicle $(3,4)$. Intravaginal as well as intrauterine immunization of women with inactivated poliovirus elicited specific antibody responses in the genital tract $(5,6)$, suggest-

Address correspondence to Dr. Rajesh K. Naz, Department of Obstetrics and Gynecology, Ullmann \#123, Albert Einstein College of Medicine, 1300 Morris Park Avenue, Bronx, NY 10461. 1993.

Received for publication 7 October 1992 and in revised form 3 June

J. Clin. Invest.

(C) The American Society for Clinical Investigation, Inc.

0021-9738/93/11/2331/08 \$2.00

Volume 92, November 1993, 2331-2338 ing that the human female genital tract is not an immunologically privileged site. If this is true then every normal healthy woman should form antisperm antibodies after exposure to sperm following intercourse. However, antisperm antibodies have been detected using various methods generally only in sera from infertile women and not in the sera from fertile women. Though various hypotheses have been proposed to explain the exact mechanism(s), the general absence of antisperm antibodies in sexually active fertile women remains an enigma.

We have isolated and characterized a sperm-specific glycoprotein, the fertilization antigen (FA-1), ${ }^{1}$ from human and murine male germ cells that seems to have a role in human fertilization (7-9). Interestingly, sera from infertile women and not from fertile women react strongly with FA-1, indicating its involvement in involuntary infertility in humans (10, 11 ). The present study was conducted to investigate whether or not sera from fertile and infertile women have antiidiotypic antibodies ( $a b-2)$ to antisperm antibodies (ab-1), especially to FA-1 antibodies. The main objective of this study was to search for mechanism(s) involved in the usually undetectable antisperm antibody response in fertile women who are sexually exposed to sperm.

\section{Methods}

Patient sera. Sera ( $n=24$, nos. 1-24) were collected from fertile healthy women (28-36 yr old) who had delivered a healthy baby within the last $2 \mathrm{yr}$. These sera were negative for antisperm antibodies as assayed by the sperm agglutination technique (SAT) (12), the sperm immobilization technique (SIT) (13), and the indirect immunobead technique (IBT) (14). Sera $(n=23$, nos. 25-47) were also collected from infertile women (26-37 yr old) who demonstrated antisperm antibodies in their sera as revealed by the SAT (titers $>1: 2,048$ ), SIT (titers $>1: 64$ ), and/or IBT ( $>50 \%$ binding). Sera ( $n$ $=12$, nos. 48-59) were collected from healthy normal virgin females (12-16 yr old).

Fertilization antigen ( $F A-1)$. FA-1 was purified from lithium diiodosalicylate (LIS)-solubilized human testes by immunoaffinity chromatography using MA-24 monoclonal antibody $(7,8)$. Each batch of FA-1 was tested for its homogeneity. Only batches that showed specific band of 49-51 kD in SDS-PAGE when stained with ultra-sensitive silver stain were used in the present study.

Antiidiotypic antibodies to FA-I monoclonal antibody. The hybridomas secreting FA-1 monoclonal antibody (MA-24) were injected into pristane-sensitized BALB/c mice to obtain ascites fluid $(7,8)$. The monovalent $\left(\mathrm{Fab}^{\prime}\right)$ antibodies were prepared from the ascites fluid (as described below), affinity purified using protein A-Sepharose 4B column, and then immunoaffinity purified using FA-1 antigen in an immunocolumn (described below). The immunoaffinity-purified FA-1

1. Abbreviations used in this paper: ab-1, antisperm antibodies; ab-2, antiidiotypic antibodies; FA-1, fertilization antigen; IBT, indirect immunobinding technique; SPA, sperm penetration assay. 
monoclonal antibody Fab' (henceforth referred to as anti-FA-1 Fab') was injected into rabbits to obtain antiidiotypic antibodies ( $R b$ ab-2). The immunization of rabbits was carried out by a procedure described elsewhere (15). Briefly, sexually mature virgin female rabbits (random-bred New Zealand white strain, $n=2$ ) were immunized by two injections simultaneously, one subcutaneously and one intramuscularly, with $125 \mu \mathrm{g}$ of immunoaffinity-purified anti-FA-1 Fab' in PBS emulsified with Freund's complete adjuvant. 2 wk after the primary injection, the rabbits were injected at each site weekly for $3 \mathrm{wk}$ with the same amount of the antigen mixed with incomplete Freund's adjuvant. 2 wk after the last injection, the animals were bled, sera collected, and Fab's prepared as described below. Rabbits $(n=2)$ injected similarly with the control monoclonal antibody Fab' yielded sera that were used to prepare Fab's, to be used as controls for the Rb ab-2 against FA-1 monoclonal antibody. The control monoclonal antibody Fab' used in the present study was prepared from control mouse myeloma ascites fluid (henceforth referred to as control Fab') of the same isotype specificity, IgG2a-, as the FA-1 monoclonal antibody (mouse IgG2a-[k] UPC10, cat. no. 50328; Cappel Labs., Organon Teknika Corp., Durham, NC).

Preparation of Fab's. The present experiments were performed using monovalent Fab's of the patient sera and rabbit antisera raised against FA-1 monoclonal antibody $\mathrm{Fab}^{\prime}$ or control myeloma ascites $\mathrm{Fab}^{\prime}$. Monovalent Fab's were prepared as described in detail elsewhere (16) by the method of Nisonoff et al. (17). Briefly, immunoglobulins were precipitated with $18 \%$ sodium sulfate, the precipitates were dialyzed against PBS, and the IgGs were affinity purified using a protein ASepharose 4B column. The affinity-purified IgGs were digested with pepsin $(2.5 \%$ [wt/wt] in $0.1 \mathrm{M}$ sodium acetate, $\mathrm{pH} 4.5$, for $18 \mathrm{~h}$ at $37^{\circ} \mathrm{C}$ ). The digested preparations were dialyzed against PBS containing $0.085 \mathrm{M} 2 \beta$-mercaptoethanol, PBS containing $13.51 \mathrm{mM}$ iodoacetamide, and finally against PBS alone. The dialyzed pepsin-digested aliquots were applied to a protein A-Sepharose 4B column, incubated, and the affinity-purified Fab' fragments of IgGs were collected as flow-through fractions. The Fab's were lyophilized, reconstituted, aliquoted, and stored at $-20^{\circ} \mathrm{C}$ for subsequent use. A portion of the $\mathrm{Fab}^{\prime}$ preparation was examined in SDS-PAGE for homogeneity and lack of intact IgG.

The affinity-purified Fab's prepared from FA-1 monoclonal antibody (MA-24) were further purified using an immunoaffinity column containing FA- 1 antigen coupled with Sepharose $4 \mathrm{~B}$ activated by $\mathrm{CNBr}$ as described elsewhere (18). After washing the column with PBS until the absorbance $\left(A_{280 \mathrm{~nm}}\right)$ became zero, the bound Fab's were eluted with $0.1 \mathrm{M}$ glycine- $\mathrm{HCl}$ buffer ( $\mathrm{pH} \mathrm{2.8)}$ ) at room temperature. The eluted fractions were immediately neutralized with $1.0 \mathrm{M} \mathrm{KH}_{2} \mathrm{PO}_{4}$, dialyzed against PBS, and stored at $-20^{\circ} \mathrm{C}$ for subsequent use.

In the Western blot procedure (described below), affinity-purified IgGs (instead of Fab's) from patient sera and rabbit sera were run in SDS-PAGE (reduced or nonreduced) and tested against the immunoaffinity-purified anti-FA-1 Fab'.

ELISA. ELISA was performed as described elsewhere $(7,18)$. Briefly, ELISA plates were coated with FA-1 antigen or anti-FA-1 Fab or control Fab' $(0.02 \mu \mathrm{g} /$ well), blocked with $0.25 \%$ BSA in PBS ( $\mathrm{pH}$ 7.4) containing $0.05 \%$ Tween-20 (PBS-BSA-Tween), washed (PBSTween), and incubated with Fab's from fertile, infertile, or virgin women $(10 \mu \mathrm{g} /$ well diluted in PBS-BSA-Tween $)$. The wells were washed (PBS-Tween), incubated with alkaline phosphatase-conjugated goat antibody to human IgG ( 1:200 dilution) (second antibody), and developed using disodium $p$-nitrophenyl phosphate (Sigma Chemical Co., St. Louis, MO) as substrate. Absorbance was measured at 405 $\mathrm{nm}$. For determining the binding of anti-FA-1 Fab' with FA-1 antigen, and the Rb ab-2 with anti-FA-1 Fab', alkaline phosphatase-conjugated goat antibodies to murine $\mathrm{IgG}$ and rabbit IgG, respectively, were used as the second antibody.

Each serum was run in duplicate with uncoated wells serving as controls. The absorbance reading of the uncoated wells was subtracted from the absorbance reading of the antigen/Fab'-coated wells, and the mean of the subtracted values was recorded. The sera were run in batches of 10-15 and tested on 2-3 different days. Absorbance readings were converted to SD units using the following formula: SD units $=$ mean (test) - mean (control) $/ \mathrm{SD}$ of the control group. Test samples with SD units of $\geq+2$ were considered as having a positive reaction with FA-1 antigen or anti-FA-1 Fab' or control Fab'.

Western blot procedure. The Western blot procedure was performed by the method of Towbin et al. (19). Briefly, $6.8 \mu \mathrm{g}$ of affinitypurified IgG was run on a 5-15\% gradient SDS gel (reduced or nonreduced) (20), transferred to nitrocellulose paper, probed first with either anti-FA-1 Fab' or control Fab' ( $15 \mu \mathrm{g} / 7 \mathrm{ml}$ of buffer), and then with alkaline phosphatase-conjugated affinity-purified anti-mouse antibody. The latter was extensively immunoadsorbed with human immunoglobulins ( $1: 1,000$ dilution, $H$ and $L$ chain specific; cat. no. AA272; The Binding Site, San Diego, CA). The bands were localized using 5-bromo-4-chloro-3-indolyl phosphate as substrate (21).

Immunoprecipitation procedure. To further confirm the presence of ab-2 in the sera of fertile women, we performed the immunoprecipitation procedure involving competitive inhibition of binding of ab-2 to anti-FA-1 Fab' by adsorption with FA-1. The affinity-purified IgG $(7.2-\mu \mathrm{g})$ samples from sera of fertile (nos. 1 and 6 ) or virgin females (nos. 49 and 50) were added to $15 \mu \mathrm{l}$ of anti-FA-1 Fab' or control Fab' covalently coupled to $\mathrm{CNBr}$-activated Sepharose-4B beads in a microcentrifuge tube, containing various concentrations of FA-1 $(0,3.5$, and $9.3 \mu \mathrm{g})$. The reaction mixture was incubated first at $37^{\circ} \mathrm{C}$ for $1 \mathrm{~h}$ and then at $5^{\circ} \mathrm{C}$ overnight on an Eppendorf shaker. The beads were centrifuged (3,000 $\mathrm{g}$ for $2 \mathrm{~min}$ ), supernatants discarded, and the pellet was washed (three times) with PBS by centrifugation. The beads were then mixed with $50 \mu$ l of SDS sample buffer (nonreduced) (20), heated in a boiling water bath for $10 \mathrm{~min}$, centrifuged again, and the supernatant was subjected to SDS-PAGE. The gels were stained using a silver staining kit following the manufacturer's protocol (Bio-Rad Laboratories, Richmond, CA) and photographed.

The anti-FA-1 Fab' and control Fab' were covalently coupled to $\mathrm{CNBr}$-activated Sepharose-4B beads (Sigma Chemical Co.) by a procedure described elsewhere $(7,8)$.

Sperm penetration assay (SPA). Assay of human sperm penetration of zona-free hamster oocytes, commonly described as SPA, was performed by the modified method of Yanagimachi et al. (22), described in detail elsewhere (18). Briefly, sperm were capacitated in test yolk buffer for $24-48 \mathrm{~h}$ at $4^{\circ} \mathrm{C}$, washed (three times), and resuspended in Biggers, Whitten, and Whittingham (BWW) containing 1\% BSA. The sperm suspension was adjusted to $5 \times 10^{6} \mathrm{sperm} / \mathrm{ml}$, a $50-\mu l$ drop containing $7 \mu \mathrm{l}$ of test solution (containing anti-FA-1 Fab' or PBSBSA) was incubated for $1.5 \mathrm{~h}$ at $37^{\circ} \mathrm{C}$, and then incubated for $3 \mathrm{~h}$ at $37^{\circ} \mathrm{C}$ with $10-20$ zona-free hamster oocytes obtained from superovulated golden hamsters. The ova were then washed, stained with acridine orange $(0.2 \%)$, and penetration was determined by the presence of fluorescing swollen sperm heads in the cytoplasm of the ovum. Motility was recorded before and after incubation with the antibody and ova. The assay was repeated two to five times using two to three fertile donors and each serum was tested with 32-91 ova. For immunoadsorption experiments, the anti-FA-1 Fab' was incubated overnight at $4^{\circ} \mathrm{C}$ with $\mathrm{Fab}$ ' samples from fertile women, the reaction mixtures were centrifuged, and the supernatants tested as described above.

$I B T$. The indirect IBT was performed as described by Bronson et al. $(11,14)$. Briefly, Fab's from infertile women (immunoadsorbed overnight at $4^{\circ} \mathrm{C}$ with PBS-BSA or Fab's from fertile women and centrifuged ) were incubated with motile, antibody-free sperm $\left(10^{6} \mathrm{sperm} /\right.$ $\mathrm{ml}$ ) collected by the swim-up procedure from fertile men. After incubation for $1 \mathrm{~h}$ at $37^{\circ} \mathrm{C}$, spermatozoa were washed free of unreacted Fab's and resuspended in PBS containing $0.1 \%$ BSA for subsequent immunobead binding (immunobeads were coated with rabbit anti-human immunoglobulins; Bio-Rad Laboratories). A positive reaction was recorded if one bead or more bound per sperm cell, and $\geq 10 \%$ motile sperm were bound.

Immunoaffinity purification of Fab's. To further confirm that the effects observed in SPA and IBT were due to the ab-2 present in sera of fertile women, we performed the immunoaffinity purification of Fab's 
from these sera. For immunoaffinity purification, the affinity-purified Fab's $(120 \mu \mathrm{g}$ ) from sera of fertile (nos. 1 and 6) or infertile women (nos. 27-29) were incubated (overnight at $4^{\circ} \mathrm{C}$ ) with either the anti$\mathrm{Fab}^{\prime}$ or control Fab' $\mathrm{CNBr}$-activated Sepharose 4B immunoadsorbent columns $(7,8)$. After washing the column at $\mathrm{pH} 8(0.1 \mathrm{M}$ phosphate buffer $)$, the bound Fab's were eluted at $\mathrm{pH} 2.8(0.1 \mathrm{M}$ glycine, $\mathrm{HCl}$ buffer $)(7,8)$. The eluted fractions were immediately neutralized with $1 \mathrm{M} \mathrm{KH}_{2} \mathrm{PO}_{4}$, concentrated, and dialyzed for $48 \mathrm{~h}$ against PBS. After dialysis the Fab's were investigated for effects on neutralization of the fertilization-inhibitory effect of anti-FA-1 Fab' in the SPA and on the inhibition of sperm-binding activity of antisperm antibodies in the IBT.

Statistical analysis. Differences between various experimental and control groups was analyzed using the paired or unpaired student's $t$ test.

\section{Results}

FA-1 used in the present studies demonstrated a single band of 49-51 kD in SDS-PAGE after staining with silver stain. Fab's purified from sera of women (fertile, infertile, and virgin ), rabbit antisera ( $\mathrm{Rb} \mathrm{Ab}-2)$ raised against anti-FA-1 monoclonal antibodies, and control myeloma ascites fluid each showed a single band of 40-42 kD. Heavier bands corresponding to intact IgG molecules were not seen in SDS-PAGE. Fab's purified from murine and rabbit sera showed a slightly lower molecule mass $(\sim 40 \mathrm{kD})$ than the corresponding Fab' purified from human sera $(\sim 42 \mathrm{kD})$ (data not shown).

When assayed against FA-1 antigen in an ELISA, none of the affinity-purified Fab's from fertile or virgin females reacted positively ( $>2$ SD units), whereas $70 \%(16 / 23)$ of the Fab's from infertile women reacted positively with the FA-1 antigen (Fig. $1 A$ ). In contrast, when these Fab's were run against the anti-FA-1 Fab', the Fab's from 71\% (17/24) of fertile women showed a positive reaction, Fab's from only three infertile women $(13 \%, 3 / 23)$ demonstrated a weak positive reaction, and none of the Fab's from any of the virgin females $(0 \%$, $0 / 12$ ) showed any positive reaction (Fig. $1 B$ ). None of the
Fab's from fertile, infertile, or virgin women reacted positively with the control Fab' (Fig. $1 C$ ). In these experiments, anti-FA$1 \mathrm{Fab}^{\prime}$ specifically reacted with the FA-1 antigen $(A)$. Rb ab-2 to anti-FA-1 Fab' specifically reacted with anti-FA-1 Fab' ( $B$, lane $a$ ) and not with control Fab' $(C$, lane $a$ ); and the specific reaction with anti-FA-1 Fab's disappeared after immunoadsorption with the FA-1 antigen $\left(B\right.$, lane $\left.a^{\prime}\right)$. Fab's prepared from preimmune sera collected from rabbits immunized with anti-FA-1 Fab's or from rabbits immunized with control Fab' did not react with anti-FA-1 Fab' (data not shown).

The presence of antiidiotypic antibodies in fertile women was confirmed by the Western blot procedure. Anti-FA-1 Fab' reacted specifically with a band corresponding to an intact IgG molecule, on a Western blot of nonreduced affinity-purified IgGs from sera of fertile women (Fig. $2 A$, lanes $a$ and $b$ ). The nonreduced IgGs from infertile women (especially no. 25) also showed some reaction with anti-FA-1 Fab'; however, the intensity of the reaction was much stronger with the IgGs from fertile women (Fig. $2 A$, lanes $c$ and $d$ ). Even IgGs from the three fertile women (nos. 4,5 , and 8 ) that showed a weaker $(<2 \mathrm{SD}$ units) reaction in ELISA reacted stronger with the anti-FA-1 Fab' in the Western blot procedure than IgGs from the infertile women. The IgGs from virgin females did not react specifically with the anti-FA-1 Fab's and the intensity of the reaction was the same as that observed with the control Fab'. The second antibody (alkaline phosphatase-conjugated affinity-purified anti-mouse IgG) used in the present study, although extensively adsorbed with human immunoglobulins (The Binding Site), showed a weak intensity of reaction, even without the control Fab' as the first antibody. The reactions, however, were specific and strongest with Fab's from fertile women, (Fig. $2 A$, lanes $a$ and $b$ ), followed by Fab's from infertile women ( $A$, lanes $c$ and $d$ ). The specific and strong reactions were observed only when intact nonreduced IgGs were used. Upon using the reduced IgGs from fertile women, the specific reactions disappeared; there were no differences in intensities of reactions whether run against the anti-FA-1 Fab'

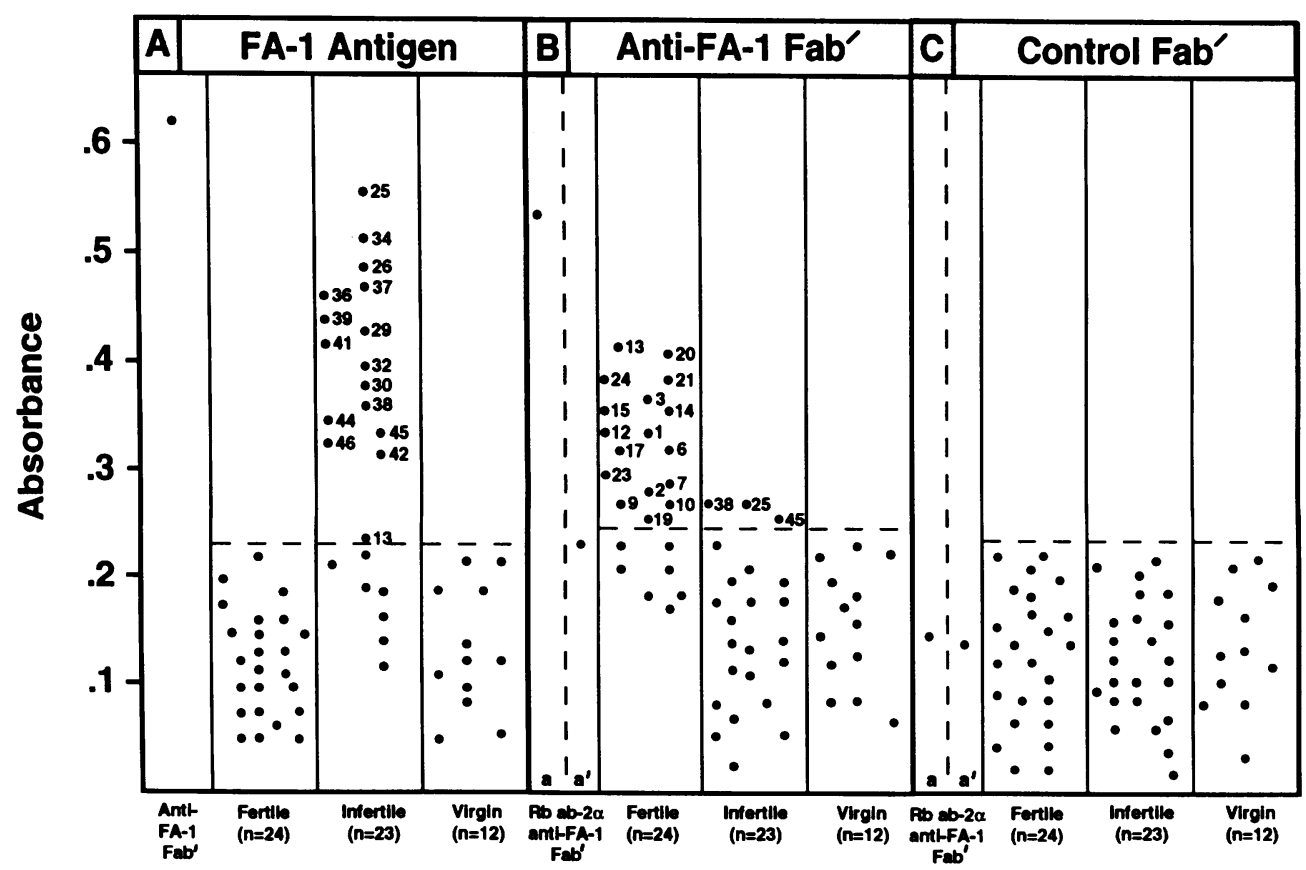

Figure 1. Reaction of Fab' antibodies present in sera of fertile, infertile, and virgin females with FA-1 antigen $(A)$, anti-FA-1 monoclonal antibody $\mathrm{Fab}^{\prime}(B)$, and control myeloma ascites fluid $\mathrm{Fab}^{\prime}(C)$ in an ELISA. Absorbance values above the horizontal dotted line represent $>2$ SD units, indicating a positive reaction. The FA-1 monoclonal antibody Fab' reacted strongly with the FA-1 antigen $(A)$. Rabbit antiidiotypic antibodies $(\mathrm{Rb}$ ab-2) to anti-FA-1 Fab' also reacted strongly with anti-FA-1 $\mathrm{Fab}^{\prime}(B$, lane $a)$; the reaction diminished when FA-1 antigen was added to compete with the antiidiotypic antibody $(B$, lane $\left.a^{\prime}\right)$. Control Fab' did not react with antiidiotypic antibodies, or $\mathrm{Rb}$ ab- 2 whether tested before $(C$, lane $a$ ) or after addition of FA-1 antigen ( $C$, lane $\left.a^{\prime}\right)$. 


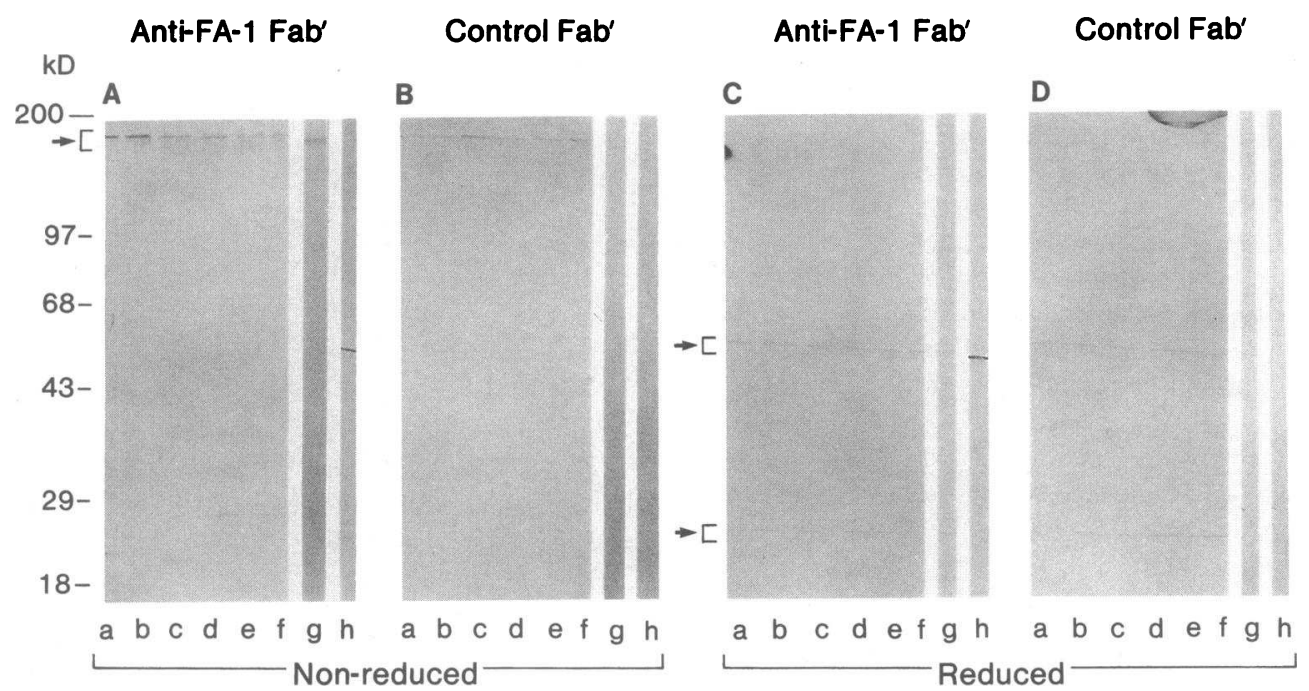

Figure 2. Presence and specificity of antiidiotypic determinants on IgGs of sera from fertile women by the Western blot procedure. Nonreduced $(A$ and $B$ ) and reduced ( $C$ and $D$ ). Two representative affinity-purified serum IgGs from fertile (lanes $a$ and $b$ ), infertile (lanes $c$ and $d$ ), and virgin women (lanes $e$ and $f$ ) are shown. The intensity of the immunoreactivity with anti-FA-1 Fab' decreased from fertile to infertile to virgin females $(A)$, with virgin females showing only a weak nonspecific reaction of the same intensity as observed with the control Fab' $^{\prime}$ $(B)$. On reduction, the intensity of the specific reactions with anti-FA-1 Fab' diminished ( $C$ and $D$ ). Anti-FA-1 Fab' recognized specifically the Rb ab-2 on the nonreduced blot $(A$, lane $g$ ) and not the reduced blot $(C$, lane $g$ ). Anti-FA-1 Fab' specifically recognized FA-1 antigen of $\sim 51 \mathrm{kD}$ on the Western blot whether reduced $(A$, lane $h)$ or nonreduced $(C$, lane $h)$.

or control Fab', or with the second antibody alone. Reduced $\mathrm{Rb}$ ab-2 against anti-FA-1 Fab' specifically reacted with the anti-FA-1 Fab' (Fig. $2 A$, lane $g$ ) and not with the control Fab' $(B$, lane $g$ ). Nonreduced $\mathrm{Rb}$ ab-2 did not react with anti-FA-1 $\mathrm{Fab}^{\prime}(C$, lane $g$ ) or with control Fab' $(D$, lane $g$ ). FA-1 antigen
( $\sim 51-\mathrm{kD}$ band) reacted specifically with the anti-FA-1 Fab' whether reduced (Fig. $2 A$, lane $h$ ) or nonreduced (Fig. $1 C$, lane $h$ ); but it did not react with control Fab' whether reduced $(B$, lane $h)$ or nonreduced $(D$, lane $h)$.

The presence of $a b-2$ in the sera of fertile women was fur-

\section{kD A Anti-FA-1 Fab'}

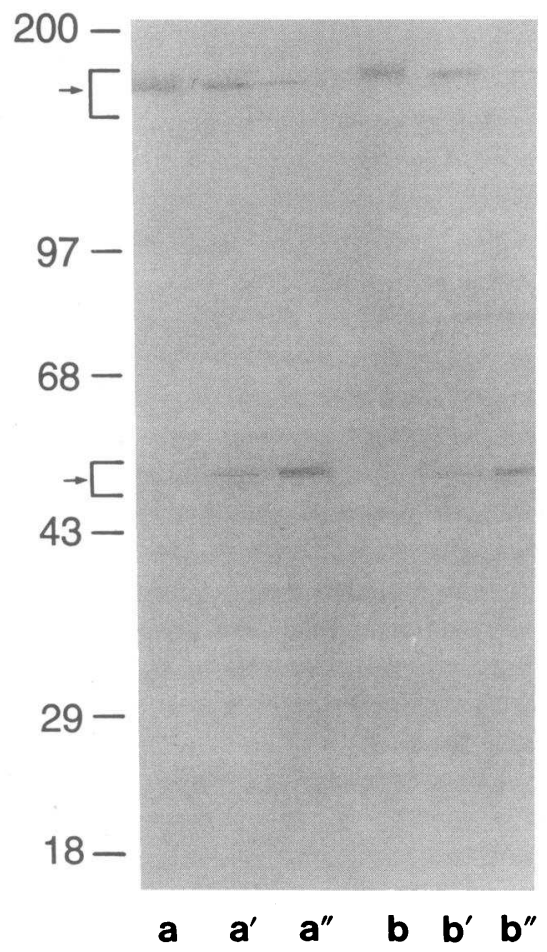

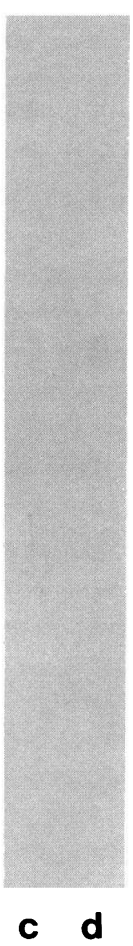

B Control Fab'

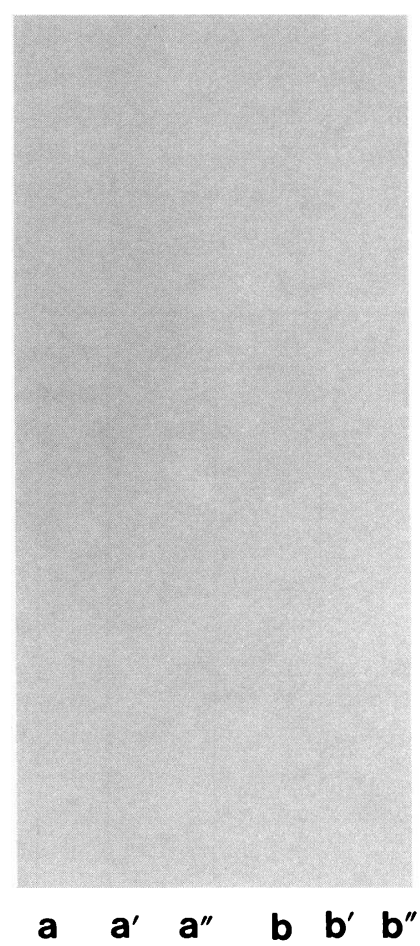

Figure 3. Confirmation of the presence of antiidiotypic antibodies in sera of fertile women by the immunoprecipitation procedure. $(A)$ Affinity-purified IgGs from two fertile women (nos. 1 and 6), specifically bound to anti-FA-1 immunoadsorbent beads, and on elution with SDS-sample buffer showed a single band corresponding to IgG in SDS-PAGE (lanes $a$ and $b$, respectively). On addition of FA-1 to the reaction mixture, there was a concentration-dependent decrease in binding of both of these IgGs with anti-FA1 immunoadsorbent beads, as seen by the decrease in intensities of these bands, with a corresponding increase in intensities of the bands corresponding to FA-1 (lanes $a^{\prime}, a^{\prime \prime}$ [no. 1] and $b^{\prime}$, $b^{\prime \prime}$ [no. 6], corresponding to 3.5 $\mu \mathrm{g}$ [ lanes $a^{\prime}$ and $b^{\prime}$ ] and $9.3 \mu \mathrm{g}$ [lanes $a^{\prime \prime}$ and $b^{\prime \prime}$ ] of FA-1, respectively). Affinity-purified IgGs from two virgin females (nos. 49 and 50), did not react with anti-FA-1 immunoadsor-

bent beads (lanes $c$ and $d$, respectively). ( $B$ ) The replica of the gel shown in $A$, with IgGs incubated with the control Fab' beads instead of antiFA-1 immunoadsorbent beads. IgG from neither of the fertile women reacted with the control beads, thus the eluate did not show any band in SDS-PAGE (lanes $a, a^{\prime}, a^{\prime \prime}$ [no. 1] and $b, b^{\prime}, b^{\prime \prime}$ [no. 6], corresponding to $0 \mu \mathrm{g}$ [lanes $a$ and $b$ ], $3.5 \mu \mathrm{g}$ [lanes $a^{\prime}$ and $b^{\prime}$ ], and $9.3 \mu \mathrm{g}$ [ $a^{\prime \prime}$ and $b^{\prime \prime}$ ] of FA-1, respectively). Similarly, IgG from neither of the virgin females reacted with control Fab' beads, thus, the eluate did not show any band in SDS-PAGE (lanes $c$ and $d$, respectively). 
ther confirmed using affinity-purified IgGs from two fertile women in the immunoprecipitation procedure. The IgGs from both fertile women (nos. 1 and 6) specifically reacted with the anti-FA-1 immunobeads with the binding competitively inhibited by FA-1 antigen in a concentration-dependent manner (Fig. $3 A$, lanes $a, a^{\prime}, a^{\prime \prime}$, and $b, b^{\prime}, b^{\prime \prime}$, respectively). These IgGs did not react with the control Fab' beads (Fig. $3 B$, lanes $a, a^{\prime}$, $a^{\prime \prime}$ and $b, b^{\prime}, b^{\prime \prime}$, respectively). The IgGs from two virgin females (nos. 49 and 50) did not react with the anti-FA-1 immunobeads (Fig. $3 A$, lanes $c$ and $d$, respectively) or with the control Fab' beads (Fig. $3 B$, lanes $c$ and $d$, respectively).

Further experiments were conducted to investigate the biological activity of the Fab's purified from the sera of fertile women. The effect of the Fab's from four fertile women on the fertilization-inhibitory activity of anti-FA-1 Fab' was assayed in the SPA (Table I). The Fab's from three women (nos. 1, 6, and 7), which showed a positive reaction with the anti-FA-1 $\mathrm{Fab}^{\prime}$ in ELISA, demonstrated a significant neutralization of the anti-FA-1 Fab'-mediated fertilization-inhibitory activity on human sperm penetration of zona-free hamster oocytes. The $\mathrm{Fab}^{\prime}$ from the fourth fertile woman (no. 8) exhibited a slight neutralization activity, however, the effects were nonsignificant. Fab's isolated from infertile women (nos. 26 and 27) had additive effects; rather than neutralizing the fertilizing-inhibi-

Table I. Effects of Antiidiotypic Antibodies Present in Sera of Fertile Women on Fertilization-inhibitory Activity of FA-1 Monoclonal Antibody

\begin{tabular}{|c|c|c|c|c|}
\hline & \multicolumn{2}{|c|}{ Immunoadsorbed with: } & \multirow{2}{*}{$\begin{array}{l}\text { No. Ova } \\
\text { tested }\end{array}$} & \multirow{2}{*}{$\begin{array}{l}\text { Sperm penetrated } \\
\text { per ovum }\end{array}$} \\
\hline & Serum (patient) & Amount & & \\
\hline$\mu g / 50 \mu l$ & & $\mu g / 50 \mu l$ & no. & mean $\pm S D$ \\
\hline \multicolumn{5}{|c|}{ FA-1 antibody } \\
\hline- & PBS-BSA & 6.2 & 53 & $28.94 \pm 3.05^{*}$ \\
\hline 3.5 & PBS-BSA & 6.2 & 49 & $18.19 \pm 1.39^{\ddagger}$ \\
\hline 3.5 & Fertile (no. 1) & 3.0 & 35 & $26.97 \pm 4.79^{\S}$ \\
\hline 3.5 & Fertile (no. 6) & 4.1 & 37 & $25.68 \pm 6.11^{\S}$ \\
\hline 3.5 & Fertile (no. 7) & 1.6 & 47 & $24.24 \pm 0.55^{\S}$ \\
\hline 3.5 & Fertile (no. 8) & 3.3 & 38 & $21.72 \pm 5.41^{11}$ \\
\hline 3.5 & Infertile (no. 26) & 3.2 & 34 & $12.10 \pm 2.32^{\ddagger}$ \\
\hline 3.5 & Infertile (no. 27) & 3.7 & 32 & $10.23 \pm 1.98^{\ddagger}$ \\
\hline 3.5 & Virgin (no. 49) & 4.3 & 39 & $17.32 \pm 2.18^{11}$ \\
\hline 3.5 & $\mathrm{Rb}$ ab-2 & 3.0 & 37 & $27.30 \pm 1.27^{\S}$ \\
\hline 3.5 & FA-1 antigen & 2.6 & 32 & $27.97 \pm 0.25^{\S}$ \\
\hline \multicolumn{5}{|l|}{ Fab's alone } \\
\hline- & PBS-BSA & 6.2 & 91 & $33.57 \pm 7.69^{1}$ \\
\hline- & Fertile (no. 1) & 3.0 & 52 & $34.77 \pm 7.86^{* *}$ \\
\hline- & Fertile (no. 6) & 3.0 & 54 & $33.91 \pm 8.44^{* *}$ \\
\hline- & Fertile (no. 7) & 1.6 & 58 & $33.38 \pm 6.67^{* *}$ \\
\hline- & Fertile (no. 8) & 3.3 & 56 & $35.99 \pm 7.30^{* *}$ \\
\hline- & Infertile (no. 26) & 3.2 & 31 & $15.63 \pm 3.23^{\ddagger \ddagger}$ \\
\hline- & Infertile (no. 27) & 3.7 & 33 & $17.61 \pm 4.23^{\ddagger \ddagger}$ \\
\hline- & Virgin (no. 49) & 4.3 & 38 & $35.15 \pm 10.39^{* *}$ \\
\hline- & $\mathrm{Rb} a b-2$ & 3.0 & 37 & $32.18 \pm 6.45^{* *}$ \\
\hline- & FA-1 antigen & 2.6 & 40 & $35.98 \pm 3.32^{* *}$ \\
\hline
\end{tabular}

In these studies, affinity-purified antibodies showing a single band of $40 \mathrm{kD}$ in SDS-PAGE were used. ${ }^{*}$ vs. ${ }^{\ddagger}, P=0.004$ to $<0.001 ;{ }^{\S}$ vs. ${ }^{\ddagger}, P=0.02$ to $0.009,{ }^{\text {" }}$ vs. ${ }^{\ddagger}$ nonsignificant $(P>0.05)$; ๆ vs. ${ }^{\ddagger \neq}, P$ $=0.004 ;{ }^{\prime}$ vs. ${ }^{* *}$, nonsignificant $(P>0.05)$. tory activity of anti-FA-1 Fab', they slightly decreased the penetration rates in comparison with using anti-FA-1 Fab's alone. Fab's from two virgin females (nos. 49 and 50) did not neutralize the fertilization-inhibitory effect of anti-FA-1 Fab'. Interestingly, both FA- 1 antigen as well as $\mathrm{Rb}$ ab- 2 showed specific and significant neutralization of the fertilization-inhibitory activity of anti-FA-1 Fab' ( Table I). None of the Fab' from fertile sera, $\mathrm{Rb}$ ab-2, or FA-1 antigen per se significantly affected the human sperm penetration rates.

To investigate further possible biologic activities of Fab's purified from sera of fertile women, they were used in adsorption experiments in an attempt to block the sperm-binding activity of Fab's from antisperm antibody-positive sera of infertile women. The inhibition of antisperm antibody binding was measured by the IBT. Indeed, the $\mathrm{ab}-2$ present in sera from all four of the fertile women tested were able to neutralize up to $100 \%$ of the sperm-binding activity of the sera examined from eight different infertile women (Table II). However, there was a large variation in the neutralization capacity among Fab's from various fertile women. Even Fab's from the same fertile woman showed a varied degree of neutralization of Fab's from different infertile women. Incubation with Fab's from virgin

Table II. Effects of Antiidiotypic Antibodies Present in Sera of Fertile Women on Sperm-binding Activity of Antisperm Antibodies Present in Sera of Infertile Women

\begin{tabular}{|c|c|c|c|c|}
\hline \multirow[b]{2}{*}{ Infertile serum } & \multicolumn{2}{|c|}{ Immunoadsorbed with: } & \multicolumn{2}{|c|}{ Immunobead binding } \\
\hline & $\begin{array}{c}\text { Serum } \\
\text { (patient) }\end{array}$ & Amount & $\begin{array}{c}\text { Percent } \\
\text { sperm } \\
\text { bound }\end{array}$ & Localization \\
\hline$\mu g / 30 \mu l$ & & $\mu g / 30 \mu l$ & & \\
\hline \multicolumn{5}{|l|}{ Infertile no. 28} \\
\hline 15 & PBS-BSA & 12.5 & 57 & Head and tail \\
\hline 15 & Fertile (no. 1) & 8.4 & 8 & Head and tail \\
\hline 15 & Fertile (no. 6) & 11.6 & 0 & - \\
\hline 15 & Fertile (no. 7) & 5.1 & 10 & Head and tail \\
\hline 15 & Fertile (no. 8) & 9.9 & 22 & Head and tail \\
\hline 15 & Virgin (no. 49) & 12.1 & 61 & Head and tail \\
\hline 15 & Virgin (no. 50) & 11.6 & 55 & Head and tail \\
\hline 15 & Infertile (no. 29) & 12.1 & 72 & Head and tail \\
\hline \multicolumn{5}{|l|}{ Infertile no. 29} \\
\hline 15 & PBS-BSA & 12.5 & 38 & Head and tail \\
\hline 15 & Fertile (no. 1) & 8.4 & 8 & Head and tail \\
\hline 15 & Fertile (no. 6) & 11.6 & 8 & Head and tail \\
\hline 15 & Fertile (no. 7) & 5.1 & 12 & Head and tail \\
\hline 15 & Fertile (no. 8) & 9.9 & 9 & Head and tail \\
\hline 15 & Infertile (no. 28) & 12.2 & 64 & Head and tail \\
\hline \multicolumn{5}{|l|}{ Infertile no. 30} \\
\hline 15 & PBS-BSA & 12.5 & 61 & Head \\
\hline 15 & Fertile (no. 6) & 11.6 & 13 & Head \\
\hline 15 & Fertile (no. 7) & 5.1 & 47 & Head \\
\hline 15 & Fertile (no. 8) & 9.9 & 22 & Head \\
\hline 15 & Infertile (no. 28) & 12.2 & 22 & Head \\
\hline
\end{tabular}

In these studies, affinity-purified Fab' antibodies showing a single band of $40 \mathrm{kD}$ in SDS-PAGE were used. Experiments were performed using sera from eight different infertile women and using sperm from at least three different donors. Three representative experiments are shown here. All these Fab's from fertile women are negative for sperm binding ( $0 \%$ binding) in the IBT. 
Table III. Effects of Immunoaffinity-purified Antiidiotypic Antibodies from Fertile Women on Fertilization-inhibitory Activity of FA-1 Monoclonal Antibody

\begin{tabular}{clccc}
\hline & \multicolumn{2}{c}{ Immunoadsorbed with: } & & \\
\cline { 2 - 3 } FA-1 antibody & Serum (patient) & Amount & Ova tested & $\begin{array}{c}\text { Sperm penetrated } \\
\text { per ovum }\end{array}$ \\
\hline$\mu g / 50 \mu l$ & & $\mu g / 50 \mu l$ & no. & Mean $\pm S D$ \\
0 & PBS-BSA & 8.9 & 48 & $23.56 \pm 3.98^{*}$ \\
8.2 & PBS-BSA & 8.9 & 43 & $2.39 \pm 0.78^{\ddagger}$ \\
8.2 & Fertile (no. 1) & 1.1 & 32 & $4.31 \pm 1.55^{\S}$ \\
8.2 & Fertile (no. 1) & 2.5 & 31 & $8.32 \pm 4.34^{\S}$ \\
8.2 & Fertile (no. 1) & 5.8 & 32 & $20.32 \pm 4.36^{\| \prime}$ \\
8.2 & Fertile (no. 1) & 8.9 & 32 & $24.32 \pm 1.98^{\| \prime}$ \\
8.2 & Fertile (no. 6) & 2.5 & 32 & $4.1 \pm 1.39^{\S}$ \\
8.2 & Fertile (no. 6) & 5.8 & 32 & $17.80 \pm 4.20^{\prime \prime}$ \\
8.2 & Fertile (no. 6) & 8.9 & 37 & $25.62 \pm 6.01^{\| \prime}$ \\
\hline
\end{tabular}

In this study, immunoaffinity-purified Fab's from fertile women having $>4 \mathrm{SD}$ units in ELISA were used. ${ }^{*}$ vs. ${ }^{\ddagger}, P<0.001 ;{ }^{\S}$ vs. ${ }^{\ddagger}$, nonsignificant $(P>0.05)$; " vs. ${ }^{\ddagger}, P=0.02-0.007$; " vs. ${ }^{*}$, nonsignificant $(P>0.05)$.

females at the same or higher concentrations did not immunoadsorb the sperm-binding activity of antisperm antibodies present in sera of infertile women. Again, incubation of the Fab's from infertile women with the Fab's from infertile women showed additive rather than neutralization effects ( Table II).

To further confirm that these biological effects were specifically due to the $a b-2$ present in sera of fertile women, ab- 2 was purified using the anti-FA-1 immunoadsorbent column. Fab's from fertile women showed specific binding to the anti-FA-1 immunoadsorbent column but not to the control Fab' column. The immunoaffinity-purified $\mathrm{Fab}^{\prime}$ fraction that eluted at $\mathrm{pH}$ 2.8 neutralized the fertilization-inhibitory activity of anti-FA-1 $\mathrm{Fab}^{\prime}$ in the SPA (Table III) and inhibited the sperm-binding activity of antisperm antibodies in the IBT in a concentrationdependent manner (Table IV). The Fab's from three infertile

Table IV. Effects of Immunoaffinity-purified Antiidiotypic Antibodies from Fertile Women on Sperm-binding Activity of Antisperm Antibodies

\begin{tabular}{clcc}
\hline \multirow{2}{*}{$\begin{array}{c}\text { Infertile serum } \\
\text { (no. 28) }\end{array}$} & \multicolumn{2}{c}{ Immunoadsorbed with: } & \\
\cline { 2 - 3 } & Serum (patient) & Amount & $\begin{array}{c}\text { Immunobead binding* } \\
\text { (sperm bound) }\end{array}$ \\
\hline$\mu g / 30 \mu l$ & & $\mu g / 30 \mathrm{ml}$ & $\%$ \\
15 & PBS-BSA & 15.1 & 62 \\
15 & Fertile (no. 1) & 3.1 & 57 \\
15 & Fertile (no. 1) & 7.2 & 32 \\
15 & Fertile (no. 1) & 8.4 & 23 \\
15 & Fertile (no. 1) & 15.1 & 14 \\
15 & Fertile (no. 6) & 4.5 & 39 \\
15 & Fertile (no. 6) & 8.3 & 23 \\
15 & Fertile (no. 6) & 11.6 & 12 \\
15 & Fertile (no. 6) & 16.2 & 6 \\
\end{tabular}

In this study, immunoaffinity-purified Fab's from fertile women having $>4$ SD units in ELISA were used. * Experiments were performed using sperm from two different fertile donors on two different days. women examined did not bind either to the anti-FA-1 immunoadsorbent column or to the control Fab' column, and thus nothing eluted at pH $2.8\left(\mathrm{~A}_{280 \mathrm{~nm}}\right.$ was 0$)$.

\section{Discussion}

The presence of ab-2 in the sera of the majority of fertile women was indicated by positive reactions of their Fab's with anti-FA-1 Fab' in ELISA, Western blot, immunoprecipitation, and immunoaffinity purification procedures. That $a b-2$ formation is a result of exposure to sperm cells is suggested by their absence in the sera of virgin women. Anti-FA-1 Fab' reacted with the immunoglobulins from fertile women only when heavy and light chains were intact, as required by the idiotypic determinants for complete expression (23). The lack of detection of serum ab- 2 in some of the fertile women could be due to the sensitivity of the methods or the amount of free ab- 2 circulating that are dependent upon the nature and kinetics of the immune response generated after exposure to sperm following intercourse. The absence or minimal presence of ab-2 against FA-1 antibodies in the sera of infertile women suggests that the antiidiotypic antibodies play a role in etiology of involuntary infertility.

Biological activity of $a b-2$ isolated from the sera of fertile women was shown by their ability to neutralize the activity of anti-FA-1 antibodies to inhibit sperm penetration of hamster eggs and to block the sperm-binding activity of antisperm antibodies present in sera of infertile women. There was a great variation in the neutralization capacity among Fab's from various fertile women. Even Fab's from the same fertile woman showed a varied degree of neutralization of the Fab's from different infertile women. This may be due to differences in antigenic specificities of the antisperm antibodies present in sera of infertile women and/or due to the differences in specificities of the ab-2 present in sera of fertile women. Indeed, the sera from various antibody-positive infertile women have been shown to react with a variety of different spermatozoal proteins on Western blots of detergent-solubilized human sperm preparations $(10,24,25)$.

In the present study, we investigated the presence of $a b-2$ in sera of fertile, infertile, and virgin women. To examine the in vivo relevance of these findings, studies need to be extended to investigate their presence in the genital tract secretions. However, the antibodies found in female genital tract secretions originate from both the mucosal immune system as well as the systemic immune system dependent on the organ (6). Ovarian follicular fluid is essentially a serum filtrate containing levels of IgA and IgG only slightly lower than serum. Cervical secretions and oviductal secretions contain approximately equal levels of IgG and IgA (mostly of the polymeric type bound to secretory component), whereas in uterine secretions IgG is dominant (6, 26). Hysterectomy with removal of the cervix results in a slight lowering of vaginal IgG but a major loss of IgA in women (3, 4). Secretory IgA, which is polymeric, arises from plasma cells located in the submucosal tissue. The origin of the plasma cells is possibly from lymphoid tissues in the peritoneal cavity and/ or is associated with the gut. IgG may also arise from locally secreting plasma cells but the majority appears to be from serum sources $(6,26)$. Thus, the immune induction of antisperm antibodies, either locally or systemically, by whatever etiology may be influenced by the antiidiotypic antibodies, especially of the IgG isotype.

The immune responses are regulated by cells (including 
their soluble mediators) and antibodies that are specific for idiotypic as well as conventional antigenic determinants. Idiotype-based regulatory systems offer the possibility of extended chains of complementary members, i.e., idiotype, antiidiotype, anti-antiidiotype, and so on. This theory of immune modulation regulated through the idiotype-antiidiotype network was postulated by Jerne (27) and has been documented in various experimental and pathological conditions (28-32). Antiidiotypic immunity has been suggested to play an important role in regulation of autoimmune responses (33). Autoimmune disease could result as a consequence of an alteration of the immunologic network, and antiidiotypic immunity has been proposed as a treatment for individuals afflicted with autoimmune disease.

Our results demonstrate for the first time that sera from fertile women who are sexually exposed to sperm have antiidiotypic antibodies that are capable of neutralizing the antisperm antibody activity. These antiidiotypic antibodies carried the internal image of the FA-1 antigen as they successively competed with FA-1 in inhibiting the binding and biologic activities of anti-FA-1 antibodies. The antiidiotypic antibodies were absent in sera of virgin females not sexually exposed to sperm. Sperm have isoantigenic potential $(1,2)$ and the female genital tract is not an immunologically privileged site (3-6), thus, antisperm antibody response may be expected after sexual exposure to sperm following intercourse. Our data suggest that normally in fertile women exposure to semen elicits a systemic immune response with antibodies against sperm, as we were able to detect the complementary antiidiotypic antibodies by several methods. Our results support the Jerne's (27) network theory of immune modulation regulated through idiotype-antiidiotype interaction. Based upon these findings one can speculate that the immune response to sperm is generated after exposure to sperm in both fertile as well as infertile women. However, in fertile women, the antisperm antibody (ab-1) generated after exposure to sperm elicits the production of antiidiotypic antibody (ab-2), which neutralizes the ab-1 response. In contrast, in infertile women, the ab- 2 production is either weak or absent, thus, it is insufficient to neutralize the ab-1 response, resulting in infertility. It can be hypothesized that immune infertility may be a consequence of derangement of the idiotype-antiidiotype network. The derangement could be the result of either: $(a)$ an inherent lack of an ab-2 response to the primary ab-1 production, or $(b)$ hyperimmunization with sperm antigens occuring due to idiopathic reasons or as a concurrent event with infection in the female genital tract with elevated ab- 1 production ensuing. Circulating antisperm antibodies have been found in women with a history of genital tract infections (26).

The above findings will have applications in the development of an antisperm contraceptive vaccine, and in the treatment of immunologic infertility. We plan to investigate whether modulation of antisperm antibody response in infertile women by in vivo injection of gamma globulins from fertile women could result in treatment of infertility. Besides the idiotype-antiidiotype network, there may be additional mechanisms such as cell-mediated immunity including suppressor $\mathrm{T}$ cells, cytotoxic $\mathrm{T}$ cells, and various cytokines (lymphokines/ monokines) involved in regulation of antigenicity of sperm cells in the female genital tract (34). Interactions between various components of the immune system in immunoregulation of sperm function require further study.

\section{Acknowledgments}

We thank Professor Betty Diamond for helpful suggestions throughout this study and Drs. Constance DiFiglia and Anjana Gupta for their help in purifying Fab's and ELISA. The superb dedicated technical assistance provided by Ms. Laura Keller, Dr. Paul Kaplan, and Ms. Derell Engel in performing SPA and IBT is gratefully acknowledged. We thank Ms. Daniela Pulitano for providing excellent typing and secretarial assistance.

A part of this work was supported by a grant from the National Institutes of Health (HD-24425 to R.K. Naz).

\section{References}

1. Liskin, L., J. M. Pile, and W. F. Quillin. 1983. Vasectomy-safe and simple Popul. Rep. 4:61-100.

2. Menge, A. C. 1980. Clinical immunological infertility: diagnostic measures, incidence of antisperm antibodies, fertility and mechanisms. In Immunological Aspects of Infertility and Fertility Regulation. D. S. Dhindsa and G. B. Schumacher, editors. Elsevier Science Publishing Co., Inc., New York. 205-225.

3. Head, J. R., and R. E. Billingham. 1986. Concerning the immunology of the uterus. Am. J. Reprod. Immunol. 10:76-81.

4. Naz, R. K., and A. C. Menge. 1990. Development of antisperm contraceptive vaccine for humans: why and How? Hum. Reprod. Oxf. 5:511-518.

5. Ogra, P. L., and S. S. Ogra. 1973. Local antibody response to polio vaccine in the human female genital tract. J. Immunol. 110:1307-1311.

6. Kutteh, W. H., R. P. Edwards, A. C. Menge, and J. Mestecky. 1992. IgA immunity in female genital tract secretions. In Proceedings of the Symposium on Local Immunity in Reproductive Tract Tissues. G. P. Talwar, editor. Cambridge University Press, Cambridge. 229-243.

7. Naz, R. K., N. J. Alexander, M. Isahakia, and M. D. Hamilton. 1984. Monoclonal antibody to a human sperm membrane glycoprotein that inhibits fertilization. Science (Wash. DC). 225:342-344.

8. Naz, R. K., T. M. Phillips, and B. B. Rosenblum. 1986. Characterization of the fertilization antigen-1 for the development of a contraceptive vaccine. Proc. Natl. Acad. Sci. USA. 83:5713-5717.

9. Naz, R. K., C. Brazil, and J. W. Overstreet. 1992. Effects of antibodies to sperm surface fertilization antigen- 1 on human sperm-zona pellucida interaction. Fertil. Steril. 57:1304-1310.

10. Naz, R. K. 1987. Involvement of fertilization antigen (FA-1) in involuntary immunoinfertility in humans. J. Clin. Invest. 80:1375-1383.

11. Bronson, R. A., G. W. Cooper, E. J. Margalioth, R. K. Naz, and M. Hamilton. 1989. The detection in human sera of antisperm antibodies reactive with FA-1, an evolutionarily conserved antigen and with murine spermatozoa. Fertil. Steril. 52:457-462.

12. Friberg, J. 1974. A simple and sensitive micromethod for demonstration of sperm-agglutinating activity in serum from infertile men and women. Acta Obstet. Gynecol. Scand. 74:21-29.

13. Isojima, S., T. S. Li, and Y. Ashitaka. 1968. Immunological analysis of sperm immobilizing factor found in sera of women with unexplained infertility. Am. J. Obstet. Gynecol. 101:677-683.

14. Bronson, R. A., G. Cooper, T. Hjort, R. Ing, W. R. Jones, S. Wang, S Mathur, H. O. Williamson, P. F. Rust, H. H. Fudenberg, L. Mettler, A. B. Czuppon, and N. Sudo. 1985. Antisperm antibodies detected by agglutination, immobilization, cytotoxicity and immunobead binding assays. J. Reprod. Immunol. 8:279-287.

15. Naz, R. K. 1990. Effects of sperm-reactive antibodies present in human infertile sera on fertility of female rabbits. J. Reprod. Immunol. 18:161-177.

16. Ahmad, K., and R. K. Naz. 1991. Antibodies to sperm surface antigens and the c-myc proto-oncogene product inhibit early embryonic development in mice. Biol. Reprod. 45:841-850.

17. Nisonoff, A., F. C. Wissler, L. N. Lipman, and D. L. Woernley. 1960. Separation of univalent fragments from the bivalent rabbit antibody molecule by reduction of disulfide bonds. Arch. Biochem. Biophys. 89:230-244.

18. Naz, R. K., J. Deutsch, T. M. Phillips, A. C. Menge, and H. Fisch. 1989 Sperm antibodies in vasectomized men and their effects on fertilization. Biol. Reprod. 41:163-173.

19. Towbin, H., T. Stachelin, and J. Gordon. 1979. Electrophoretic transfer of proteins from polyacrylamide gels to nitrocellulose sheets: Procedures and some applications. Proc. Natl. Acad. Sci. USA. 76:4350-4354.

20. Laemmli, U. K. 1970. Cleavage of structural proteins during the assembly of the head of bacteriophage $\mathrm{T}_{4}$. Nature (Lond.). 220:680-685.

21. Naz, R. K. 1992. Effects of antisperm antibodies on early cleavage of fertilized ova. Biol. Reprod. 46:130-139.

22. Yanagimachi, R., H. Yanagimachi, and B. J. Rogers. 1976. The use of 
zona-free animal ova as a test-system for the assessment of the fertilizing capacity of human spermatozoa. Biol. Reprod. 45:471-476.

23. Rajewsky, K., and T. Takemori. 1983. Genetics, expression and function of idiotypes. Annu. Rev. Immunol. 1:569-607.

24. Naaby-Hansen, S., and O. J. Bjerrum. 1985. Auto- and isoantigens of human spermatozoa detected by immunoblotting with human sera after SDSPAGE. J. Reprod. Immunol. 7:41-57.

25. Lee, C-Y. G., V. Lum, E. Wong, A. C. Menge, and Y-S. Huang. 1983. Identification of human sperm antigens to antisperm antibodies. Am. J. Reprod. Immunol. 3:183-187.

26. Menge, A. C. 1993. Mucosal immunity of the reproductive tract and infertility. In Immunology of Reproduction. R. K. Naz, editor. CRC Press, Inc. Boca Raton, FL. 19-36.

27. Jerne, N. K. 1974. Towards a network theory of the immune response. Ann. Immunol. (Paris). 125C:373-387.

28. Dwyer, D. S., R. J. Bradley, C. Kendrich-Urquhar, and J. F. Kearney. 1983. Naturally occurring anti-idiotypic antibodies in myasthenia gravis patients. Nature (Lond.). 30:611-614.

29. Zanetti, M., and P. E. Bigazzi. 1981. Anti-idiotypic immunity and autoim- munity. I. In vitro and in vivo effects of anti-idiotypic antibodies to spontaneously occurring autoantibodies to rat thyroglobulin. Eur. J. Immunol. 11:187195.

30. Halpern, R., A. Davidson, A. Lazo, G. Solomon, R. Lahita, and B. Diamond. 1985. Familial systemic lupus erythematosus: presence of a cross-reactive idiotype in healthy family members. J. Clin. Invest. 76:731-736.

31. Reagan, K. J., W. H. Wunner, T. J. Witkor, and H. Koprowski. 1983. Anti-idiotypic antibodies induce neutralizing antibodies to rabies virus glycoprotein. J. Virol. 48:660-666.

32. Bona, C. A., E. Heber-Katz, and W. E. Paul. 1981. Idiotype-anti-idiotype regulation. 1. Immunization with a levan-binding myeloma protein leads to the appearance of auto-anti-(anti-idiotype) antibodies and to the activation of silent clones. J. Exp. Med. 153:951-967.

33. Bigazzi, P. E. 1986. Anti-idiotypic immunity in autoimmunity. Ann. NY Acad. Sci. 475:66-80.

34. Naz, R. K. 1993. Role of cell-mediated immunity in infertility. In Immunology of Reproduction. R. K. Naz, editor. CRC Press, Inc., Boca Raton, FL. 61-80. 